\title{
Epidemiology of human parechovirus, Aichi virus and salivirus in fecal samples from hospitalized children with gastroenteritis in Hong Kong
}

Cyril C Y Yip ${ }^{1}$, Kin-Land Lo', Tak-Lun Que ${ }^{5}$, Rodney A Lee ${ }^{6}$, Kwok-Hung Chan ${ }^{1}$, Kwok-Yung Yuen 1,2,3,4, Patrick C Y Woo ${ }^{1,2,3,4^{*}}$ and Susanna K P Lau ${ }^{1,2,3,4^{*}}$

\begin{abstract}
Background: Emerging human picornaviruses, including human parechovirus (HPeV), Aichi virus (AiV) and salivirus (SalV) were found to be associated with gastroenteritis, but their roles in enteric infections are not fully understood. In addition, no report on the circulation of these viruses in Hong Kong is available. The objective of this study was to investigate the prevalence and genetic diversity of HPeV, AiV and SalV in fecal samples from hospitalized children with gastroenteritis in Hong Kong.

Methods: Fecal samples from hospitalized children with gastroenteritis were subject to detection of HPeV, AiV and SalV by RT-PCR using consensus primers targeted to their $5^{\prime} U T R s$. Positive samples were subject to capsid and/or $3 C D$ region analysis for genotype determination. The epidemiology of HPeV, AiV and SalV infections was analyzed.

Results: Among 1,708 fecal samples subjected to RT-PCR using primers targeted to 5'UTR of HPeV, AiV and SalV, viruses were detected in 55 samples, with 50 positive for HPeV only, 3 positive for AiV only, 1 positive for both HPeV and AiV, and 1 positive for both HPeV and SalV. Phylogenetic analysis of the partial VP1 gene of the $33 \mathrm{HPeV}$ strains revealed the presence of genotypes of HPeV- $1,3,4,5,7,10$, among which HPeV-1 was the predominant genotype circulating in our population. The peak activity of HPeV infection was in fall. Of the 3 children with AiV infection, the 3 AiV strains were found to belong to genotype A based on the phylogenetic analysis of their partial VP1 and 3CD regions. The genotype of a SalV strain detected in this study could not be determined. Co-detection of different pathogens was observed in 24 samples (43.6\%) of 55 fecal samples positive for HPeV, AiV and SalV.

Conclusions: HPeV, AiV and SalV were detected in fecal samples of hospitalized children with gastroenteritis in Hong Kong, with the former having the highest prevalence. HPeV-1 was the predominant genotype among HPeVs, while genotype A was the predominant genotype among Aivs in this study.
\end{abstract}

Keywords: Human parechovirus, Aichi virus, Salivirus, Gastroenteritis, Fecal, children, Hong Kong

\section{Background}

Picornaviruses are single-stranded positive-sense RNA viruses that can cause a variety of diseases in humans and animals. Based on genotypic and serological characterization, picornaviruses are divided into 26 genera, including

\footnotetext{
* Correspondence: pcywoo@hkucc.hku.hk; skplau@hkucc.hku.hk 'Department of Microbiology, The University of Hong Kong, Hong Kong, Hong Kong

${ }^{2}$ State Key Laboratory of Emerging Infectious Diseases, The University of Hong Kong, University Pathology Building, Queen Mary Hospital, Hong Kong, Hong Kong

Full list of author information is available at the end of the article
}

Aphthovirus, Aquamavirus, Avihepatovirus, Avisivirus, Cardiovirus, Cosavirus, Dicipivirus, Enterovirus, Erbovirus, Gallivirus, Hepatovirus, Hunnivirus, Kobuvirus, Megrivirus, Mischivirus, Mosavirus, Oscivirus, Parechovirus, Pasivirus, Passerivirus, Rosavirus, Salivirus, Sapelovirus, Senecavirus, Teschovirus and Tremovirus (http://www.picornaviridae. $\mathrm{com} /$ ). In the past few years, there has been a dramatic increase in the number of novel picornaviruses identified and genome sequenced [1-12]. Picornaviruses are also well known for their ability to undergo mutations and recombination, which may lead to the emergence of novel genotypes associated with increase virulence [13-16].

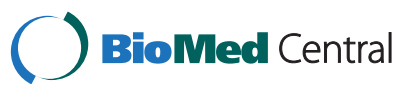

(C) 2014 Yip et al.; licensee BioMed Central Ltd. This is an Open Access article distributed under the terms of the Creative Commons Attribution License (http://creativecommons.org/licenses/by/4.0), which permits unrestricted use, distribution, and reproduction in any medium, provided the original work is properly credited. The Creative Commons Public Domain Dedication waiver (http://creativecommons.org/publicdomain/zero/1.0/) applies to the data made available in this article, unless otherwise stated. 
Diarrhea is one of the leading causes of death in the world [17], especially for children below 5 years of age. Since around $40 \%$ of the cases remain undiagnosed [18], research has been conducted to identify unrecognized causative agents. Recent advanced molecular techniques have allowed the discovery of novel viruses including picornaviruses from patients with gastroenteritis [2,18-22]. Human parechoviruses (HPeVs) have been classified into 16 types (http://www.picornaviridae.com/parechovirus/ hpev/hpev.htm), in which types $1,3-6,8,10$ and 11 were found to be associated with gastroenteritis [23-28]. $\mathrm{HPeVs}$ have been reported in fecal samples from patients with gastroenteritis in various parts of the world, suggesting that the viruses are circulating worldwide [23-28]. Another picornavirus, Aichi virus (AiV), which belongs to the genus Kobuvirus, was first isolated from a patient with oyster-associated gastroenteritis by BSC-1 cell culture in Japan in 1989 [29] and its complete genome sequence was determined in 1998 [21]. Epidemiological studies on AiV have demonstrated a global distribution of this virus [30-37]. Based on phylogenetic analysis of the sequences between the C-terminus of $3 \mathrm{C}$ and the $\mathrm{N}$-terminus of $3 \mathrm{D}, \mathrm{AiV}$ isolates were divided into 3 genotypes: A, B and a newly proposed genotype C $[30,33,36,38]$. Most recently, salivirus (SalV) or klassevirus, which belongs to the genus Salivirus, was identified in pediatric stool samples from patients with diarrhea $[2,39,40]$. Based on the results from genomic characterization, SalV was most closely related to, but distinct from other members of the genus Kobuvirus. To date, only few studies reported the molecular epidemiology of SalV infection [40-42].

Although previous findings revealed the existence of $\mathrm{HPeV}, \mathrm{AiV}$ and SalV, the roles of these viruses in enteric infections are not fully understood. In addition, no report on the circulation of these viruses in Hong Kong is available. Therefore, a molecular epidemiological study was conducted to investigate the prevalence and genetic diversity of these viruses in the fecal samples from pediatric patients with gastroenteritis in Hong Kong by reverse transcription-polymerase chain reaction (RT-PCR) using consensus primers targeted to their $5^{\prime}$ untranslated regions (5'UTRs). Phylogenetic analysis of other gene regions (capsid or $3 \mathrm{CD}$ region) was performed to determine the genotype of the HPeV, AiV and SalV.

\section{Results}

Detection of HPeV, AiV and SalV in fecal samples from pediatric patients with acute gastroenteritis

One thousand four hundred and forty fecal samples (retrospective study period) and 268 fecal samples (prospective study period) from hospitalized children with gastroenteritis were screened for the presence of $\mathrm{HPeV}$, AiV and SalV by RT-PCR using primers targeted to their corresponding 5'UTR. RT-PCR for HPeV, AiV and SalV was positive in 55 samples from 49 patients, among which 52 (3.4\% for retrospective, $1.1 \%$ for prospective) from 47 patients contained $\mathrm{HPeV}, 4 \mathrm{(0.28 \%}$ for retrospective) from 3 patients contained $\mathrm{AiV}$ (1 co-detected in a sample with $\mathrm{HPeV}$ strain patient 30/HK/May05) and 1 ( $0.07 \%$ for retrospective) contained SalV (co-detected in a sample with $\mathrm{HPeV}$ strain patient $28 / \mathrm{HK} / \mathrm{Mar} 05$ ) by sequencing and phylogenetic analysis (Figure 1). Among the 6 patients with multiple detections, the sequences of the picornavirus strains persistently shed from the same patient were identical.

The characteristics of the 49 patients with HPeV, AiV and SalV detected in fecal samples were summarized in Table 1 . The median age of the 47 patients with $\mathrm{HPeV}$ was 17 months (range, 2 months - 8 years). Thirtythree were male and 14 were female. HPeV was detected nearly throughout the year in the retrospective period (November 2004 to August 2005, and August to October 2006), with the highest detection frequency in fall (Figure 2), while 3 cases of $\mathrm{HPeV}$ infection were identified in September and November 2012, and in August 2013. HPeV was repeatedly detected in separate fecal samples from 5 patients (patient 3, 19, 22, 23, and 33). Diarrheal pathogens were frequently found in the HPeVpositive fecal samples, with rotavirus identified in 8 , norovirus in 1, human bocavirus (HBoV) in 2, AiV in 1 , SalV in 1, Salmonella enterica serotypes in 5, Campylobacter jejuni in 1, Staphylococcus aureus in 7, enteropathogenic Escherichia coli in 1, and Aeromonas species in 2.

The median age of the 3 patients with AiV was 2 years (age range being 8 months - 7 years; $\mathrm{M}: \mathrm{F}=1: 2$ ). The 4 AiV positive samples were detected in late winter and early summer in 2005 (Table 1). AiV was detected in a 7-year-old girl (patient 48) in 2 separate fecal samples collected on the same day. Co-detection of $\mathrm{HPeV}$ was found in an AiV-positive sample.

For SalV, the virus was detected in the fecal sample from an 8-year-old girl (patient 28) in March 2005. This fecal sample was co-detected with HPeV. No AiV and SalV were detected in fecal samples collected during September 2012 - August 2013.

\section{Genotyping of HPeV, AiV and SalV strains}

To determine the genotype of the HPeV, AiV and SalV strains detected in this study, amplification and sequencing of their partial VP1 capsid gene and/or 3CD region were performed. For $\mathrm{HPeV}$, partial VP1 gene of $33 \mathrm{HPeV}$ strains was successfully amplified and sequenced. A phylogenetic tree using nucleotide sequences of the partial VP1 gene of HPeV strains detected in Hong Kong and other HPeV strains with VP1 gene sequences available in GenBank was constructed (Figure 3). The 33 $\mathrm{HPeV}$ strains detected in the present study consisted of 


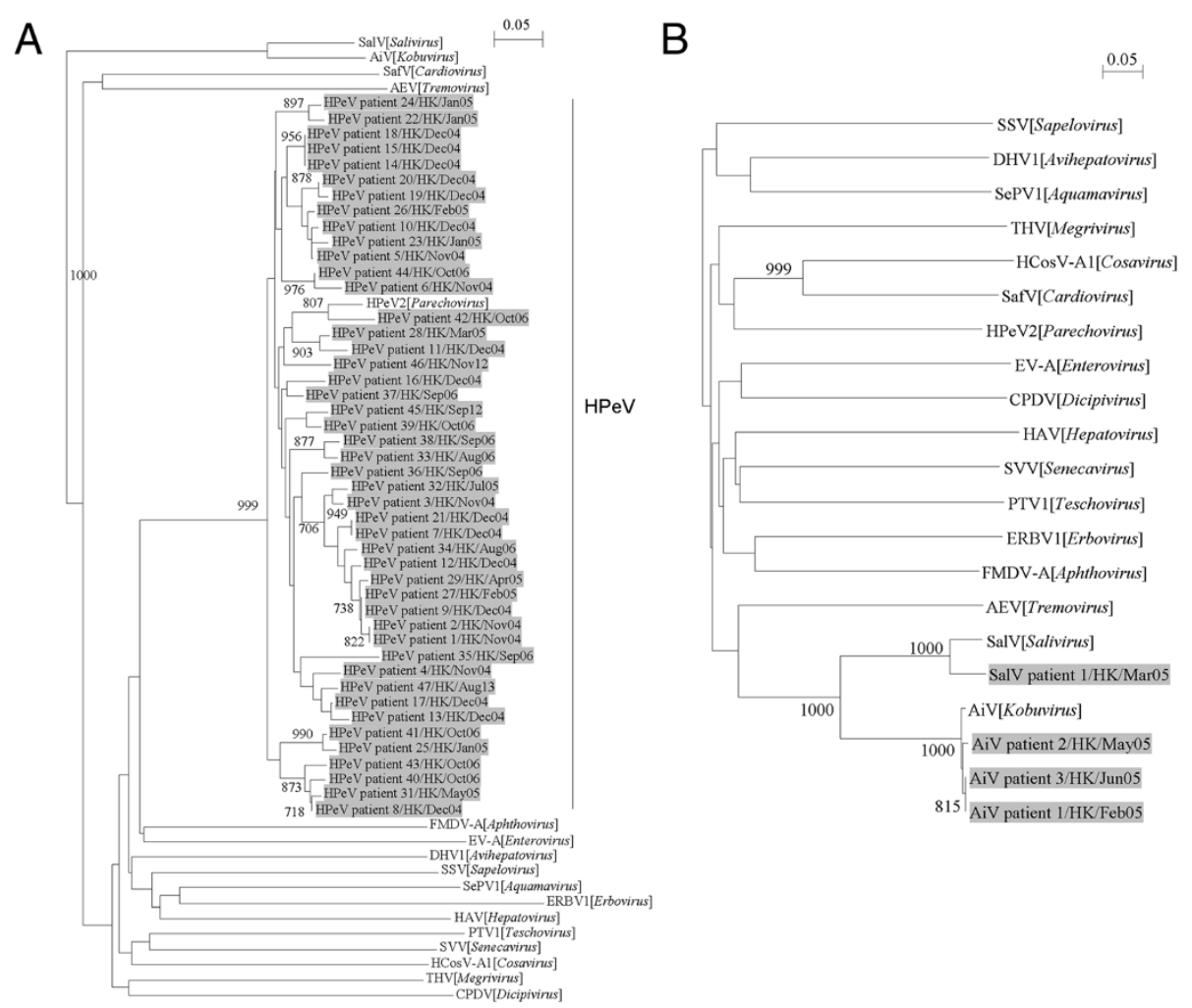

Figure 1 Phylogenetic analysis of partial 5'UTR sequences of (A) HPeV strains from 47 patients, (B) 3 AiV and 1 SalV strains from 4 patients. The trees were inferred from 5'UTR data by the neighbor-joining method, with bootstrap values calculated from 1000 trees. (A) 145 and (B) 188 nucleotide positions in each 5'UTR were included in the analysis. The scale bar indicates the estimated number of substitutions of 20 nucleotides as indicated. The virus strains detected in this study are highlighted in grey. Virus abbreviations (GenBank accession numbers shown in parentheses): AEV, avian encephalomyelitis virus (NC_003990); AiV, Aichi virus (NC_001918); CPDV, canine picodicistrovirus (JN_819202); DHV1, duck hepatitis virus 1 (NC_008250); ERBV1, equine rhinitis B virus 1 (NC_003983); FMDV-A, foot-and-mouth disease virus-A (JQ_082983); HAV, hepatovirus (NC_001489); HCosV-A1, human cosavirus A1 (FJ_4389020); EV-A, human enterovirus A (AY_697458); HPeV2, human parechovirus type-2 (AJ_005695); PTV1, porcine teschovirus 1 (NC_003985); SafV, saffold virus (EF_165067); SalV, salivirus (GQ_179640); SePV1, seal picornavirus 1 (NC_009891); SSV, simian sapelovirus (AY_064708); SW, Seneca Valley virus (NC_011349); THV, turkey hepatitis virus (HQ_189775).

6 types, including type 1 (23 strains), type 3 (2 strains), type 4 ( 3 strains), type 5 ( 2 strains), type 7 ( 2 strains) and type 10 ( 1 strain), indicating that $\mathrm{HPeV}-1$ was the predominant genotype circulating in our population. Among the $5 \mathrm{HPeV}$-positive patients with multiple detections by RT-PCR targeted to 5'UTR, the partial VP1 gene of the strains shed from 2 of these patients could be amplified and the partial VP1 sequences of the $\mathrm{HPeV}$ strains from the same patient were found to be identical.

For the genotyping of AiV, the partial VP1 capsid gene and $3 \mathrm{CD}$ region of all $3 \mathrm{AiV}$ strains were amplified and sequenced. A phylogenetic analysis of nucleotide sequences of the partial VP1 gene of AiV showed that 2 AiV strains (AiV patient 1/HK/Feb05 and AiV patient 3/ HK/Jun05) were closely related and formed a clade distinct from another strain $\mathrm{AiV}$ patient 2/HK/May05. Nevertheless, these $3 \mathrm{AiV}$ strains clustered with genotype A strains identified in other countries (Figure 4A). This was consistent with the phylogenetic result using nucleotide sequences of the partial $3 \mathrm{CD}$ region of $\mathrm{AiV}$
(Figure 4B). These findings suggested that only one genotype, genotype $\mathrm{A}$, of $\mathrm{AiV}$ was detected in Hong Kong in 2005. For the AiV-positive patient with multiple detections, the partial VP1 and 3CD sequences of AiV strains shed from the same patient were identical. For the genotyping of SalV, the partial VP1 gene and 3CD region of the SalV strain detected in this study could not be amplified, thus the genotype of this strain cannot be determined.

\section{Discussion}

The present study represented the first to report the detection of $\mathrm{HPeV}$, AiV and SalV in fecal samples from children with gastroenteritis in Hong Kong. HPeVs were distributed globally and found to be associated with acute gastroenteritis [23-28]. A number of studies have shown that the prevalence of $\mathrm{HPeV}$ infections in children with diarrhea ranged from $2 \%-16.3 \%$ in various countries $[19,23,24,43]$, and it could be as high as $55 \%$ in China [28]. In the present study, the prevalence of $\mathrm{HPeV}$ 
Table 1 Clinical characteristics and demographic data of the 49 patients with HPeV, AiV and SalV detected in fecal samples

\begin{tabular}{|c|c|c|c|c|c|c|}
\hline Patient & $\begin{array}{l}\text { Month of } \\
\text { detection }\end{array}$ & Sex & Age & $\begin{array}{l}\text { Virus identified } \\
\text { in this study }\end{array}$ & $\begin{array}{l}\text { Other pathogens detected } \\
\text { from fecal samples }\end{array}$ & $\begin{array}{c}\text { Multiple detections } \\
\text { (days apart) }\end{array}$ \\
\hline 1 & Nov 2004 & M & 3 & HPeV & None & ND \\
\hline 2 & Nov 2004 & M & $4 \mathrm{~m}$ & HPeV-1 & None & ND \\
\hline 3 & Nov 2004 & $\mathrm{~F}$ & $10 \mathrm{~m}$ & HPeV-1 & None & Yes (0) \\
\hline 4 & Nov 2004 & M & 2 & HPeV-1 & Rotavirus & ND \\
\hline 5 & Nov 2004 & M & $2 \mathrm{~m}$ & HPeV-1 & $\mathrm{HBOV}$ & ND \\
\hline 6 & Nov 2004 & M & $6 \mathrm{~m}$ & HPeV-1 & S. aureus & ND \\
\hline 7 & Dec 2004 & $\mathrm{~F}$ & 1 & HPeV & None & ND \\
\hline 8 & Dec 2004 & M & $7 \mathrm{~m}$ & $\mathrm{HPeV}-3$ & S. aureus, HBoV & ND \\
\hline 9 & Dec 2004 & $\mathrm{~F}$ & $5 \mathrm{~m}$ & HPeV-1 & S. aureus, rotavirus & ND \\
\hline 10 & Dec 2004 & M & 2 & HPeV-1 & Rotavirus & ND \\
\hline 11 & Dec 2004 & M & $6 \mathrm{~m}$ & HPeV & None & ND \\
\hline 12 & Dec 2004 & $\mathrm{~F}$ & $10 \mathrm{~m}$ & HPeV & Rotavirus & ND \\
\hline 13 & Dec 2004 & M & 2 & HPeV-1 & None & ND \\
\hline 14 & Dec 2004 & $\mathrm{~F}$ & 1 & HPeV-1 & None & ND \\
\hline 15 & Dec 2004 & M & 1 & $\mathrm{HPeV}$ & None & ND \\
\hline 16 & Dec 2004 & $\mathrm{~F}$ & $6 \mathrm{~m}$ & HPeV & S. aureus & ND \\
\hline 17 & Dec 2004 & M & $5 \mathrm{~m}$ & HPeV-1 & None & ND \\
\hline 18 & Dec 2004 & $\mathrm{~F}$ & 3 & HPeV-1 & Rotavirus & ND \\
\hline 19 & Dec 2004 & M & 1 & HPeV-1 & None & Yes (15) \\
\hline 20 & Dec 2004 & M & $8 \mathrm{~m}$ & HPeV-1 & None & ND \\
\hline 21 & Dec 2004 & M & $6 \mathrm{~m}$ & HPeV & S. aureus & ND \\
\hline 22 & Jan 2005 & $F$ & 1 & HPeV-7 & None & Yes (0) \\
\hline 23 & Jan 2005 & $F$ & $5 \mathrm{~m}$ & HPeV & None & Yes (26) \\
\hline 24 & Jan 2005 & M & $5 \mathrm{~m}$ & HPeV-7 & Rotavirus & ND \\
\hline 25 & Jan 2005 & M & $9 \mathrm{~m}$ & HPeV-1 & None & ND \\
\hline 26 & Feb 2005 & M & $6 \mathrm{~m}$ & HPeV-1 & None & ND \\
\hline 27 & Feb 2005 & M & $5 \mathrm{~m}$ & HPeV-1 & None & ND \\
\hline 28 & Mar 2005 & $\mathrm{~F}$ & 8 & HPeV-4, SalV & None & ND \\
\hline 29 & Apr 2005 & $F$ & 1 & HPeV-1 & Salmonella group B, Campylobacter jejuni & ND \\
\hline 30 & May 2005 & M & 2 & HPeV-4, AiV & Salmonella group B & ND \\
\hline 31 & May 2005 & M & $9 \mathrm{~m}$ & $\mathrm{HPeV}-3$ & Aeromonas sobria & ND \\
\hline 32 & Jul 2005 & M & 1 & HPeV-5 & Enteropathogenic E. coli & ND \\
\hline 33 & Aug 2006 & $\mathrm{~F}$ & $7 \mathrm{~m}$ & HPeV-4 & None & Yes (5) \\
\hline 34 & Aug 2006 & M & $10 \mathrm{~m}$ & HPeV-1 & S. aureus & ND \\
\hline 35 & Sep 2006 & M & 3 & HPeV-1 & None & ND \\
\hline 36 & Sep 2006 & M & $8 \mathrm{~m}$ & HPeV-5 & Salmonella group D & ND \\
\hline 37 & Sep 2006 & $\mathrm{~F}$ & 1 & HPeV-1 & Salmonella group C & ND \\
\hline 38 & Sep 2006 & M & 3 & HPeV & None & ND \\
\hline 39 & Oct 2006 & M & 1 & HPeV-10 & Rotavirus & ND \\
\hline 40 & Oct 2006 & M & 1 & HPeV & S. aureus, Salmonella group B & ND \\
\hline 41 & Oct 2006 & $\mathrm{~F}$ & $5 \mathrm{~m}$ & HPeV-1 & None & ND \\
\hline 42 & Oct 2006 & M & 3 & $\mathrm{HPeV}$ & None & ND \\
\hline 43 & Oct 2006 & M & $6 \mathrm{~m}$ & $\mathrm{HPeV}$ & None & ND \\
\hline
\end{tabular}


Table 1 Clinical characteristics and demographic data of the 49 patients with HPeV, AiV and SalV detected in fecal samples (Continued)

\begin{tabular}{|c|c|c|c|c|c|c|}
\hline 44 & Oct 2006 & M & $2 \mathrm{~m}$ & HPeV-1 & Rotavirus & ND \\
\hline 45 & Sep 2012 & M & 7 & HPeV-1 & Aeromonas veronii biovar sobria & ND \\
\hline 46 & Nov 2012 & M & $9 \mathrm{~m}$ & $\mathrm{HPeV}$ & Norovirus & ND \\
\hline 47 & Aug 2013 & M & 7 & $\mathrm{HPeV}$ & None & ND \\
\hline 48 & Feb 2005 & $\mathrm{~F}$ & 7 & AiV & None & Yes $(0)$ \\
\hline 49 & Jun 2005 & $\mathrm{~F}$ & $8 \mathrm{~m}$ & AiV & None & ND \\
\hline
\end{tabular}

HBoV, human bocavirus; E. coli, Escherichia coli; S. aureus, Staphylococcus aureus; ND, not done.

infections was around 3\%, which was similar to that in a study from Korea but lower than that reported in other studies $[19,23,24,28,43]$. HPeV infection was revealed to predominate in fall, which was in line with other studies in mainland China and Japan demonstrating that the highest detection rate of $\mathrm{HPeV}$ was noted during the autumn season $[25,44]$. The reason for the high prevalence of $\mathrm{HPeV}$ during autumn is not known. Further studies are required to evaluate if temperature and relative humidity may be important determining factors. Of the 52 samples from 47 patients with $\mathrm{HPeV}$ infections, all showed positive in children who were $\leq 8$ years old, with the majority $(25 / 47,53 \%)$ being younger than one year old. This indicated that $\mathrm{HPeV}$ infections mainly occurred in infants and younger children, which was consistent with the previous findings $[23,43]$. In one case, a 1-yearold boy (patient 41) had a hospital-acquired HPeV-1 infection after an operation, suggesting that infection control measures may be required in controlling nosocomial transmission of $\mathrm{HPeV}$. Another picornavirus, AiV, has been proposed to be a causative agent of gastroenteritis [21]. Several studies have demonstrated that the

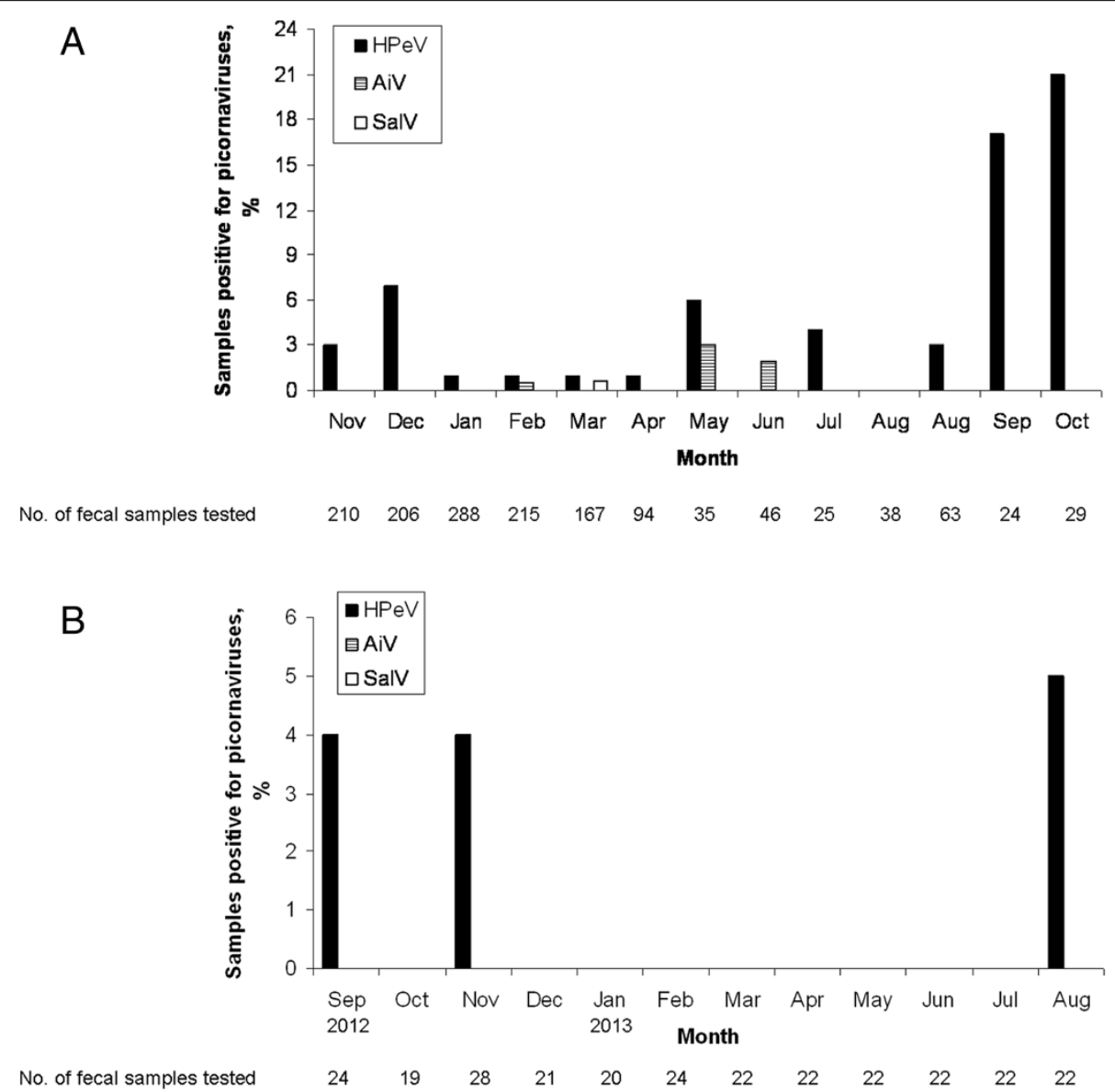

Figure 2 Seasonality distribution of HPeV, AiV and SalV infections in (A) November 2004 to August 2005 and August 2006 to October 2006 and (B) September 2012 to August 2013. 


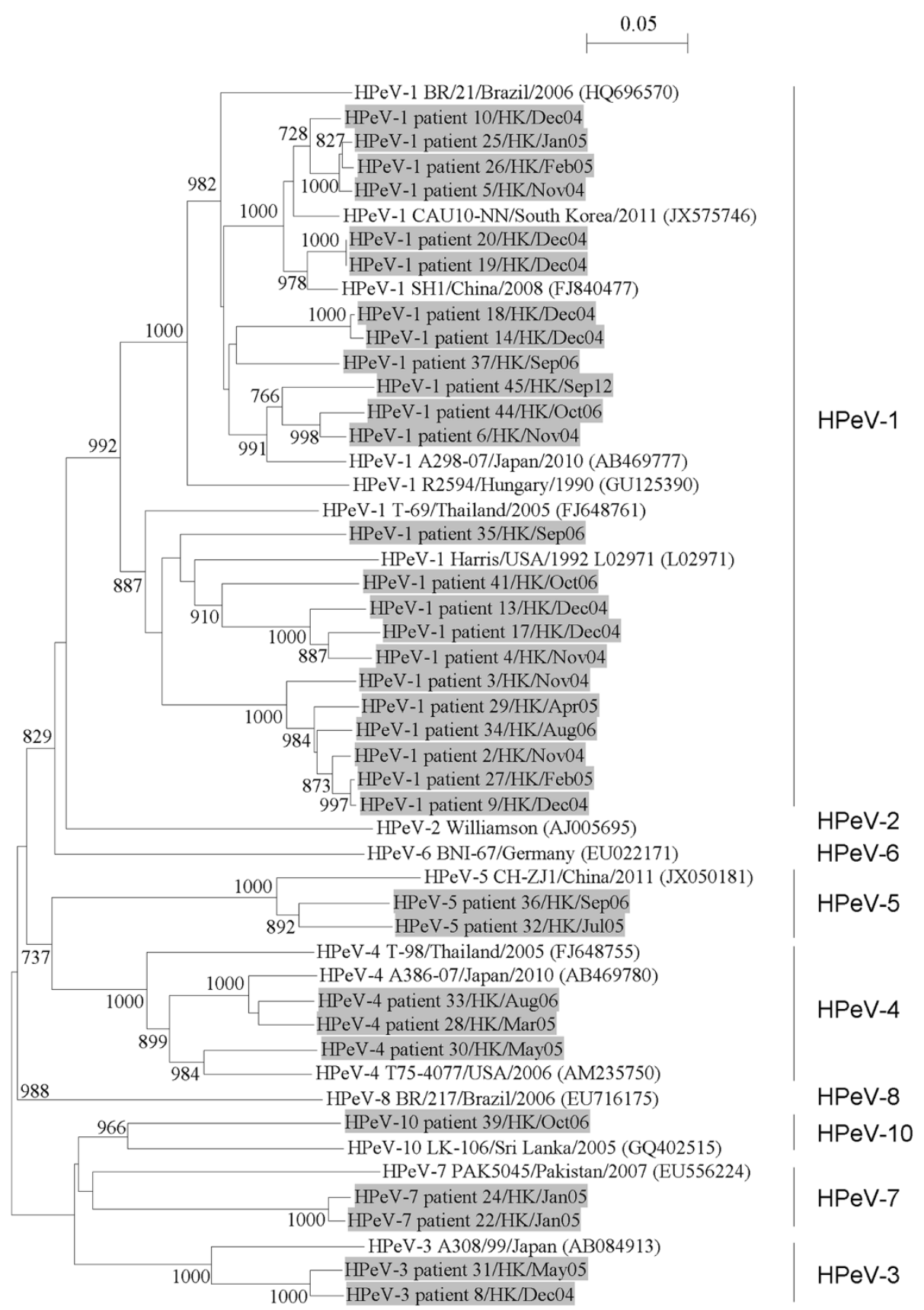

Figure 3 Phylogenetic analysis of the partial VP1 capsid gene of the $33 \mathrm{HPeV}$ strains. The trees were constructed by the neighbor-joining method, with bootstrap values calculated from 1000 trees. Sequence for 628 nucleotide positions in VP1 gene was included in the analysis. The scale bar indicates the estimated number of substitutions of 20 nucleotides as indicated. The HPeV strains detected in the present study are highlighted in grey.

prevalence of $\mathrm{AiV}$ infections in pediatric patients with diarrhea ranged from $0.1 \%-4.1 \%$ in America, Asia, Europe and Africa $[31,34,37,45-48]$. The low prevalence of AiV infections (around $0.2 \%$ ) in the present study was similar to that reported in a study from Canada [45]. Although the present study and most other studies showed low detection frequency of $\mathrm{AiV}$ in clinical specimens of patients with gastroenteritis, a high level of seroprevalence of AiV $(>80 \%)$ in adults has been demonstrated [49], suggesting the widespread of human exposure to AiV during childhood. The high seroprevalence together with low detection rate of $\mathrm{AiV}$ in gastroenteritis indicated that $\mathrm{AiV}$ infections are usually asymptomatic or mild. A recently identified picornavirus, SalV, was found to be associated with 

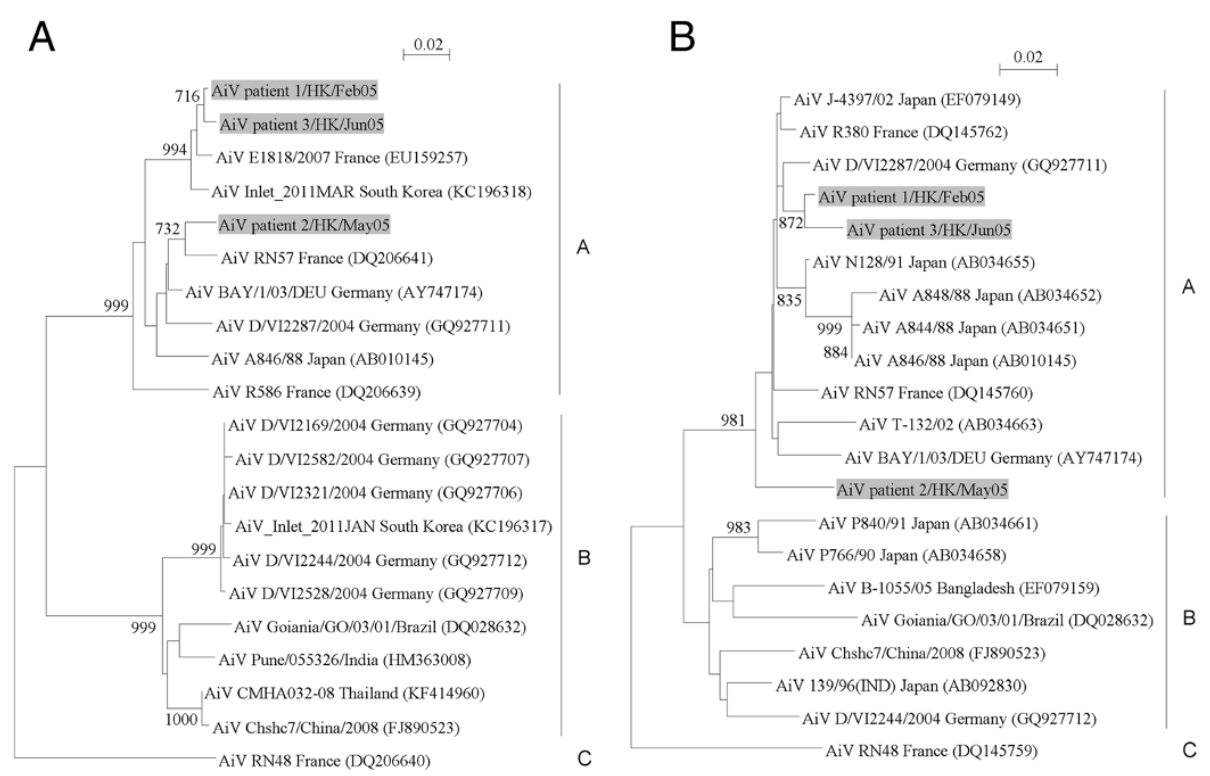

Figure 4 Phylogenetic trees of AiV strains from 3 patients. (A) Sequence for 295 nucleotide position in VP1 gene was included in the analysis. (B) Sequence for 342 nucleotide positions in partial 3CD region was included in the analysis. The trees are inferred by the neighbor-joining method with bootstrap value calculated from 1000 trees. The scale bar indicates the estimated number of substitutions of 50 nucleotides as indicated. The AiV strains detected in the present study are highlighted in grey.

gastroenteritis [40]. The prevalence of SalV infection $(<0.1 \%)$ in this study was far lower than that reported in other studies $[39,41,42]$. In the only available study from China, SalV was detected in $9(4.2 \%)$ of 216 diarrhea samples and $0(0 \%)$ of 96 control samples [42]. The differences in the prevalence of $\mathrm{HPeV}$, AiV and SalV infections among various countries were probably attributed to different sampling sources and detection methods (e.g. conventional RT-PCR, nested RT-PCR and real-time PCR), and variations in geographic and temporal conditions. While the present study aims to study the epidemiology of the novel picornaviruses instead of developing an improved diagnostic assay, it would be interesting to compare our detection method and other methods in future studies for their performance in diagnosis of $\mathrm{HPeV}, \mathrm{AiV}$ and SalV infections.

The present data suggested that HPeV-1 was the predominant genotype among $\mathrm{HPeVs}$, while genotype A was the predominant genotype among AiVs in Hong Kong. Phylogenetic analysis using the partial VP1 gene sequences of $\mathrm{HPeV}$ strains revealed that $23(70 \%)$ of 33 typeable $\mathrm{HPeV}$ strains were closely related to $\mathrm{HPeV}-1$ strains identified in other countries. In addition to $\mathrm{HPeV}-1$, other $\mathrm{HPeV}$ genotypes, including types 3, 4, 5, 7 and 10 , were detected in the present fecal samples. The low detection frequency of these 5 genotypes was also noted in previous studies showing that they were the rare $\mathrm{HPeV}$ genotypes identified in fecal samples from hospitalized patients $[24,26,43]$. To determine the genotype of $\mathrm{AiV}$, the $3 \mathrm{CD}$ region of $\mathrm{AiV}$ was sequenced. Since capsid region is also commonly used for genotypic determination of other picornaviruses, we also sequenced the partial VP1 gene for phylogenetic analysis. The clustering pattern in the phylogenetic tree constructed using the partial VP1 gene sequences of AiV was in agreement with that using $3 \mathrm{CD}$ region (Figure 4). This demonstrated that genotype of AiV can be well determined by using either VP1 or $3 \mathrm{CD}$ sequences. The $3 \mathrm{AiV}$ strains in this study clustered with other known genotype A strains, indicating that only AiV strains of genotype A were circulating in Hong Kong in 2005. However, we failed to determine the genotype of the SalV strain from patient 1/ HK/Mar05, which may be due to low viral load in the samples and/or sequence mismatches between primers and viral gene sequences.

Co-detection of various diarrheal pathogens by PCR or culture previously was observed in fecal samples positive for $\mathrm{HPeV}$ in the present study. The frequency of codetection in $\mathrm{HPeV}$-positive fecal samples in this study (46.2\%; 24/52) was in line with 2 previous studies from China showing the co-detection rate ranged from $52.3 \%$ $71.4 \%$ in fecal samples of children with acute gastroenteritis $[44,50]$, suggesting that co-detection is common for $\mathrm{HPeV}$. Further studies are required to determine whether $\mathrm{HPeV}$ plays a causative role in these co-infections or act to exacerbate the disease caused by another pathogen. Besides, multiple virus detection was observed in 5 patients with $\mathrm{HPeV}$ infection in this study, in which persistent $\mathrm{HPeV}$ shedding for more than 2-week period was noted in fecal samples of patient 19 and patient 23. The prolonged shedding was probably due to the incomplete 
clearance of the virus by the immune system of the patients. Further investigation is warranted to examine the duration of $\mathrm{HPeV}$ shedding.

There are several limitations in this study. Firstly, the difference in epidemiological findings between the retrospective and prospective periods might be attributable to the different sample size (1440 and 268 respectively). Further study is warranted to collect more fecal samples for subsequent prospective analysis. Secondly, there is lack of data for the presence of other enteric viruses including enteric adenovirus, sapovirus, torovirus and astrovirus in the picornavirus-positive fecal samples, so the co-detection rate might be underestimated. Further investigation is required to determine if they are present in the samples. Thirdly, the inclusion of control groups in future may help examine the association between the picornaviruses (HPeV, AiV and SalV) and gastroenteritis.

\section{Conclusions}

Emerging human picornaviruses including $\mathrm{HPeV}, \mathrm{AiV}$ and SalV were detected in fecal samples of children with acute gastroenteritis in our locality. HPeV is the most prevailing virus with peak activity in fall in Hong Kong. The role of AiV and SalV in gastroenteritis remains uncertain because the number of AiV/SalV-positive samples was too small in the present study. Routine surveillance for these viruses in young children with gastroenteritis may better define their epidemiology and help prevent their transmission.

\section{Methods}

\section{Patients and microbiological methods}

A total of 1,708 fecal samples in this study were collected from hospitalized pediatric patients (age $<18$ years old) with gastroenteritis, which was defined as the development of acute diarrhea with 3 or more loose stools per day. All samples were obtained from three public hospitals in Hong Kong. A retrospective study during a 13-month period (November 2004 to August 2005 and August 2006 to October 2006) and a prospective study during a 12-month period (September 2012 to August 2013) were conducted. All fecal samples were tested for common bacterial diarrheal pathogens, rotavirus by antigen detection, norovirus by RT-PCR and $\mathrm{HBoV}$ by PCR [20]. The laboratory results of patients positive for $\mathrm{HPeV}$, AiV and SalV were analyzed retrospectively. The study was approved by the Institutional Review Board of the University of Hong Kong/Hospital Authority Hong Kong West Cluster.

\section{RNA extraction}

Viral RNA was extracted from fecal samples using EZ1 Virus Mini Kit v2.0 (QIAgen, Hilden, Germany). The RNA was eluted in $60 \mu \mathrm{l}$ of AVE buffer and was used as the template for RT-PCR.

\section{RT-PCR for picornaviruses}

RT was performed using random hexamers and the SuperScript III kit (Invitrogen, San Diego, CA, USA) as described previously [14-16]. PCR for HPeV, AiV and SalV was performed using two sets of primers designed by multiple alignments of 5 'UTR nucleotide sequences of the corresponding picornaviruses (Table 2). Each PCR mixture $(25 \mu \mathrm{l})$ contained cDNA, PCR buffer, $2 \mathrm{mM}$ $\mathrm{MgCl}_{2}$, a $200 \mu \mathrm{M}$ concentration of each deoxynucleoside triphosphate, and 1.0 U Taq polymerase (Boehringer, Mannheim, Germany). The mixtures were amplified by 50 cycles of $94^{\circ} \mathrm{C}$ for $1 \mathrm{~min}, 55^{\circ} \mathrm{C}$ for $1 \mathrm{~min}$, and $72^{\circ} \mathrm{C}$ for $1 \mathrm{~min}$, with a final extension at $72^{\circ} \mathrm{C}$ for $10 \mathrm{~min}$. The amplified products were detected by agarose gel electrophoresis. Both strands of PCR products were sequenced twice with an ABI Prism 3730xl DNA Analyzer (Applied Biosystems, Foster City, CA, USA), using the PCR primers. The nucleotide sequences were compared to the corresponding sequences of other picornaviruses available in the GenBank.

\section{Phylogenetic analysis}

To determine the genotype of $\mathrm{HPeV}, \mathrm{AiV}$ and SalV detected in fecal samples, partial capsid and/or 3CD regions of these viruses were amplified and sequenced. Partial VP1 fragments of HPeV, AiV and SalV were amplified using three sets of primers designed by multiple alignments of VP1 nucleotide sequences of the corresponding

Table 2 Primers used in this study

\begin{tabular}{|c|c|c|c|c|}
\hline Virus & Forward primer sequence $\left(5^{\prime}-3^{\prime}\right)$ & Reverse primer sequence $\left(5^{\prime}-3^{\prime}\right)$ & PCR product size (Target) & Purpose \\
\hline $\mathrm{HPeV}$ & CCYCTGGGSCCAAAAGSCA & GGTACCTYCWGGGCATCCTT & 145 bp (5'UTR) & Screening of HPeV \\
\hline AiV/SalV & CTGAGAMGRYGTTCCGCTGT & GACAATTAGCCCAGGSTCAGAT & $215 \mathrm{bp}\left(5^{\prime} \cup T R\right)$ & Screening of AiV/SalV \\
\hline $\mathrm{HPeV}$ & TCATGGGGTTCNCARATGGA & GATACCATAGTGYTTRTARAA & $774 \mathrm{bp}$ & Amplification of VP1 region \\
\hline AiV & TCTTCTCCTTCTACCGCTTG & GAGGTGTAGGGGATGGAGAA & $357 \mathrm{bp}$ & Amplification of VP1 region \\
\hline AiV & GCCAGTACAAGGACATGCGG & CGGTTGACGTTGACGCCAGG & $381 \mathrm{bp}$ & Amplification of $3 C D$ region \\
\hline SalV & CCCCRTCAACTTCCAGCAAA & ACACGAACGATRGAGGTGCT & $482 \mathrm{bp}$ & Amplification of VP1 region \\
\hline SalV & GAGGGCACCGACCTGGATGC & TGGTTGATGAGAGAACCAAG & $439 \mathrm{bp}$ & Amplification of 3D region \\
\hline
\end{tabular}


picornaviruses (Table 2). Partial 3CD regions of AiV and SalV were amplified using two sets of primers designed by multiple alignment of 3C-3D nucleotide sequences of the corresponding picornaviruses (Table 2). Both strands of PCR products were sequenced twice with an ABI Prism 3730xl DNA Analyzer (Applied Biosystems, Foster City, CA, USA), using the PCR primers. The nucleotide sequences of the partial VP1 gene or 3CD region of the virus strains identified in the present study were compared to the corresponding sequences of other strains available in the GenBank. Phylogenetic tree construction was performed using neighbor-joining method with GrowTree using Kimura's two-parameter correction, with bootstrap values calculated from 1000 trees (Genetics Computer Group, Inc.).

\section{Nucleotide sequence accession numbers}

The partial VP1 nucleotide sequences of the $\mathrm{HPeV}$ and $\mathrm{AiV}$ strains and 3CD nucleotide sequences of the AiV strains have been lodged within the GenBank database under accession numbers KJ796868-KJ796906.

\section{Abbreviations}

HPeV: Human parechovirus; AiV: Aichi virus; SalV: Salivirus; RT-PCR: Reverse transcription polymerase chain reaction; UTR: Untranslated region; HBoV: Human bocavirus; HK: Hong Kong.

\section{Competing interests}

The authors declare that they have no competing interests.

\section{Authors' contributions}

CCYY, KYY, PCYW and SKPL designed the study. SKPL, TLQ, RAL and KHC collected clinical specimens and data. CCYY and KLL conducted experiments. CCYY and SKPL analyzed and interpreted data. CCYY, KLL, KYY, PCYW and SKPL wrote the manuscript. All authors read and approved the final manuscript.

\section{Acknowledgement}

We are grateful to the generous support of Mrs. Carol Yu, Professor Richard Yu, Mr. Hui Hoy and Mr. Hui Ming in the genomic sequencing platform. This work is supported by the Research Grant Council Grant, University Grant Council; and Consultancy Service for Enhancing Laboratory Surveillance of Emerging Infectious Disease for the HKSAR Department of Health.

\section{Author details \\ ${ }^{1}$ Department of Microbiology, The University of Hong Kong, Hong Kong, Hong Kong. ${ }^{2}$ State Key Laboratory of Emerging Infectious Diseases, The University of Hong Kong, University Pathology Building, Queen Mary Hospital, Hong Kong, Hong Kong. ${ }^{3}$ Research Centre of Infection and Immunology, The University of Hong Kong, Hong Kong, Hong Kong. ${ }^{4} \mathrm{Carol}$ Yu Centre for Infection, The University of Hong Kong, Hong Kong, Hong Kong. ${ }^{5}$ Department of Pathology, Tuen Mun Hospital, Hong Kong, Hong Kong. ${ }^{6}$ Department of Pathology, Pamela Youde Nethersole Eastern Hospital, Hong Kong, Hong Kong.}

Received: 22 May 2014 Accepted: 12 October 2014 Published: 18 October 2014

\section{References}

1. Chiu CY, Greninger AL, Kanada K, Kwok T, Fischer KF, Runckel C, Louie JK, Glaser CA, Yagi S, Schnurr DP, Haggerty TD, Parsonnet J, Ganem D, DeRisi J: Identification of cardioviruses related to Theiler's murine encephalomyelitis virus in human infections. Proc Natl Acad Sci U S A 2008, 105:14124-14129.
2. Greninger AL, Runckel C, Chiu CY, Haggerty T, Parsonnet J, Ganem D, DeRisi J: The complete genome of klassevirus-a novel picornavirus in pediatric stool. Virol J 2009, 6:82

3. Jones MS, Lukashov W, Ganac RD, Schnurr DP: Discoery of a novel human picornavirus in stool sample from a pediatric patient presenting fever of unknown origin. J Clin Microbiol 2007, 45:2144-2150.

4. Kapoor A, Victoria J, Simmonds P, Slikas E, Chieochansin T, Naeem A, Shaukat S, Sharif S, Alam MM, Angez M, Wang C, Shafer RW, Zaidi S, Delwart E: A highly prevalent and genetically diversified Picornaviridae genus in South Asian children. Proc Natl Acad Sci U S A 2008, 105:20482-20487.

5. Kapoor A, Victoria J, Simmonds P, Wang C, Shafer RW, Nims R, Nielsen O, Delwart E: A highly divergent picornavirus in a marine mammal. J Virol 2008, 82:311-320.

6. Lau SK, Woo PC, Lai KK, Huang Y, Yip CC, Shek CT, Lee P, Lam CS, Chan KH, Yuen KY: Complete genome analysis of three novel picornaviruses from diverse bat species. J Virol 2011, 85:8819-8828.

7. Lau SK, Yip CC, Lin AW, Lee RA, So LY, Lau YL, Chan KH, Woo PC, Yuen KY: Clinical and molecular epidemiology of human rhinovirus $C$ in children and adults in Hong Kong reveals a possible distinct human rhinovirus $\mathrm{C}$ subgroup. J Infect Dis 2009, 200:1096-1103.

8. Lau SK, Yip CC, Tsoi HW, Lee RA, So LY, Lau YL, Chan KH, Woo PC, Yuen KY: Clinical features and complete genome characterization of a distinct human rhinovirus (HRV) genetic cluster, probably representing a previously undetected HRV species, HRV-C, associated with acute respiratory illness in children. J Clin Microbiol 2007, 45:3655-3664.

9. Woo PC, Lau SK, Huang Y, Lam CS, Poon RW, Tsoi HW, Lee P, Tse H, Chan AS, Luk G, Chan KH, Yuen KY: Comparative analysis of six genome sequences of three novel picornaviruses, turdiviruses 1, 2 and 3, in dead wild birds, and proposal of two novel genera, Orthoturdivirus and Paraturdivirus, in the family Picornaviridae. J Gen Virol 2010, 91:2433-2448.

10. Lau SK, Woo PC, Yip CC, Choi GK, Wu Y, Bai R, Fan RY, Lai KK, Chan KH, Yuen KY: Identification of a novel feline picornavirus from the domestic cat. J Virol 2012, 86:395-405.

11. Woo PC, Lau SK, Choi GK, Yip CC, Huang Y, Tsoi HW, Yuen KY: Complete genome sequence of a novel picornavirus, canine picornavirus, discovered in dogs. J Virol 2012, 86:3402-3403.

12. Woo PC, Lau SK, Choi GK, Huang Y, Teng JL, Tsoi HW, Tse H, Yeung ML, Chan $\mathrm{KH}$, Jin DY, Yuen KY: Natural occurrence and characterization of two internal ribosome entry site elements in a novel virus, canine picodicistrovirus, in the picornavirus-like superfamily. J Virol 2012, 86:2797-2808.

13. Yip CC, Lau SK, Zhou B, Zhang MX, Tsoi HW, Chan KH, Chen XC, Woo PC, Yuen KY: Emergence of enterovirus 71 "double-recombinant" strains belonging to a novel genotype $D$ originating from southern China: first evidence for combination of intratypic and intertypic recombination events in EV71. Arch Virol 2010, 155:1413-1424.

14. Yip CC, Lau SK, Woo PC, Chan KH, Yuen KY: Complete genome sequence of a coxsackievirus A22 strain in Hong Kong reveals a natural intratypic recombination event. J Virol 2011, 85:12098-12099.

15. Yip CC, Lau SK, Lo JY, Chan KH, Woo PC, Yuen KY: Genetic characterization of EV71 isolates from 2004 to 2010 reveals predominance and persistent circulation of the newly proposed genotype $D$ and recent emergence of a distinct lineage of subgenotype C2 in Hong Kong. Virol J 2013, 10:222.

16. Yip CC, Lau SK, Woo PC, Wong SS, Tsang TH, Lo JY, Lam WK, Tsang CC, Chan KH, Yuen KY: Recombinant coxsackievirus A2 and deaths of children, Hong Kong, 2012. Emerg Infect Dis 2013, 19:1285-1288.

17. World Health Organization: The 10 leading causes of death in the world, 2000 and 2012. http://www.who.int/mediacentre/factsheets/fs310/en/

18. Finkbeiner SR, Allred AF, Tarr PI, Klein EJ, Kirkwood CD, Wang D: Metagenomic analysis of human diarrhea: viral detection and discovery. PLoS Pathog 2008, 4:e1000011.

19. Drexler JF, Grywna K, Stocker A, Almeida PS, Medrado-Ribeiro TC, Eschbach-Bludau M, Petersen N, da Costa-Ribeiro-Jr H, Drosten C: Novel human parechovirus from Brazil. Emerg Infect Dis 2009, 15:310-313.

20. Lau SK, Yip CC, Que TL, Lee RA, Au-Yeung RK, Zhou B, So LY, Lau YL, Chan $\mathrm{KH}$, Woo PC, Yuen KY: Clinical and molecular epidemiology of human bocavirus in respiratory and fecal samples from children in Hong Kong. J Infect Dis 2007, 196:986-993.

21. Yamashita T, Sakae K, Tsuzuki H, Suzuki Y, Ishikawa N, Takeda N, Miyamura T, Yamazaki S: Complete nucleotide sequence and genetic organization of Aichi virus, a distinct member of the Picornaviridae associated with acute gastroenteritis in humans. J Virol 1998, 72:8408-8412. 
22. Lau SK, Yip CC, Lung DC, Lee $P$, Que TL, Lau YL, Chan KH, Woo PC, Yuen KY: Detection of human rhinovirus $C$ in fecal samples of children with gastroenteritis. J Clin Virol 2012, 53:290-296.

23. Benschop K, Thomas X, Serpenti C, Molenkamp R, Wolthers K: High prevalence of human parechovirus (HPeV) genotypes in the Amsterdam region and identification of specific $\mathrm{HPeV}$ variants by direct genotyping of stool samples. J Clin Microbiol 2008, 46:3965-3970.

24. Han TH, Kim CH, Park SH, Chung JY, Hwang ES: Detection of human parechoviruses in children with gastroenteritis in South Korea. Arch Virol 2011, 156:1471-1475.

25. Ito M, Yamashita T, Tsuzuki H, Kabashima Y, Hasegawa A, Nagaya S, Kawaguchi M, Kobayashi S, Fujiura A, Sakae K, Minagawa H: Detection of human parechoviruses from clinical stool samples in Aichi, Japan. J Clin Microbiol 2010, 48:2683-2688

26. Pham NT, Takanashi S, Tran DN, Trinh QD, Abeysekera C, Abeygunawardene A, Khamrin P, Okitsu S, Shimizu H, Mizuguchi M, Ushijima H: Human parechovirus infection in children hospitalizaed with acute gastroenteritis in Sri Lanka. J Virol 2011, 49:364-366.

27. Pham NT, Trinh QD, Khamrin P, Maneekarn N, Shimizu H, Okitsu S, Mizuguchi M, Ushijima H: Diversity of human parechoviruses isolated from stool samples collected from Thai children with acute gastroenteritis. J Clin Microbiol 2010, 48:115-119.

28. Zhong $H$, Lin $Y$, Sun J, Su L, Cao L, Yang Y, Xu J: Prevalence and genotypes of human parechovirus in stool samples from hospitalized children in Shanghai, China, 2008 and 2009. J Med Virol 2011, 83:1428-1434.

29. Yamashita T, Kobayashi S, Sakae K, Nakata S, Chiba S, Ishihara Y, Isomura S: Isolation of cytopathic small round viruses with BS-C-1 cells from patients with gastroenteritis. J Infect Dis 1991, 164:954-957.

30. Ambert-Balay K, Lorrot M, Bon F, Giraudon H, Kaplon J, Wolfer M, Lebon P, Gendrel D, Pothier P: Prevalence and genetic diversity of Aichi virus strains in stool samples from communit and hospitalized patients. $J$ Clin Microbiol 2008, 46:1252-1258.

31. Kaikkonen S, Rasanen S, Ramet M, Vesikari T: Aichi virus infection in children with acute gastroenteritis in Finland. Epidemiol Infect 2010, 138:1166-1171.

32. Oh DY, Silva PA, Hauroeder B, Diedrich S, Cardoso DDP, Schreier E: Molecular characterization of the first Aichi viruses isolated in Europe and in South America. Arch Virol 2006, 151:1199-1206.

33. Pham NT, Khamrin P, Nguyen TA, Kanti DS, Phan TG, Okitsu S, Ushijima H: Isolation and molecular characterization of Aichi viruses from fecal specimens collected in Japan, Bangladesh, Thailand, and Vietnam. J Clin Microbiol 2007, 45:2287-2288.

34. Sdiri-Loulizi K, Hassine M, Gharbi-Khelifi H, Sakly N, Chouchane S, Guediche MN, Pothier P, Aouni M, Ambert-Balay K: Detection and genomic characterization of Aichi viruses in stool samples from children in Monastir, Tunisia. J Clin Microbiol 2009, 47:2275-2278.

35. Verma H, Chitambar SD, Gopalkrishna V: Circulation of Aichi virus genotype $B$ strains in children with acute gastroenteritis in India. Epidemiol Infect 2011, 139:1687-1691.

36. Yamashita T, Sakae K, Kobayashi S, Ishihara Y, Miyake T, Mubina A, Isomura S: Isolation of cytopathic small round virus (Aichi virus) from Pakistani children and Japanese travelers from Southeast Asia. Microbiol Immunol 1995, 39:433-435.

37. Yang S, Shen Q, Yang Z, Zhu J, Cui L, Hua X, Zhang W: Aichi virus strains in children with gastroenteritis, China. Emerg Infect Dis 2009, 15:1703-1705.

38. Yamashita T, Sugiyama M, Tsuzuki H, Sakae K, Suzuki Y, Miyazaki Y: Application of a reverse transcription-PCR for identification and differentiation of Aichi virus, a new member of the Picornavirus family associated with gastroenteritis in humans. J Clin Microbio/ 2000, 38:2955-2961.

39. Holtz LR, Finkbeiner SR, Zhao G, Kirkwood CD, Girones R, Pipas JM, Wang D: Klassevirus I, a previously undescribed member of the family Picornaviridae, is globally widespread. Virol J 2009, 6:86

40. Li L, Victoria J, Kapoor A, Blinkova O, Wang C, Babrzadeh F, Mason CJ, Pandey P, Triki H, Bahri O, Oderinde BS, Baba MM, Bukbuk DN, Besser JM, Bartkus JM, Delwart E: A novel picornavirus associated with gastroenteritis. J Virol 2009, 83:12002-12006.

41. Han TH, Kim CH, Chung JY, Park SH, Hwang ES: Klassevirus infection in chidren, South Korea. Emerg Infect Dis 2010, 16:1623-1625.

42. Shan T, Wang C, Cui L, Yu Y, Delwart E, Zhao W, Zhu C, Lan D, Dai X, Hua X: Picornavirus salivirus/klassevirus in children with diarrhea, China. Emerg Infect Dis 2010, 16:1303-1305.
43. Pham NT, Chan-It W, Khamrin P, Nishimura S, Kikuta H, Sugita K, Baba T, Yamamoto A, Shimizu H, Okitsu S, Mizuguchi M, Ushijima H: Detection of human parechovirus in stool samples collected from children with acute gastroenteritis in Japan during 2007-2008. J Med Virol 2011, 83:331-336.

44. Zhang DL, Jin Y, Li DD, Cheng WX, Xu ZQ, Yu JM, Jin M, Yang SH, Zhang Q, Cui SX, Liu N, Duan ZJ: Prevalence of human parechovirus in Chinese children hospitalized for acute gastroenteritis. Clin Microbiol Infect 2011, 17:1563-1569.

45. Houde A, Poitras E, Leblanc D, Ward P, Onglis GD, Boras VF, Loisy-Hamon F, Lebeau B: Aichi virus in Alberta, Canada: a one year examination of human diarrheic stool samples by RT-PCR. In Current Research, Technology and Education Topics in Applied Microbiology and Microbial Biotechnology. Edited by Mendez-Vilas A. 2010:767-772.

46. Le Guyader FS, Le Saux JC, Ambert-Balay K, Krol J, Serais O, Parnaudeau S, Giraudon H, Delmas G, Pommepuy M, Pothier P, Atmar RL: Aichi virus, norovirus, astrovirus, enterovirus, and rotavirus involved in clinical cases from a French oyster-related gastroenteritis outbreak. J Clin Microbiol 2008, 46:4011-4017.

47. Drexler JF, Baumgarte S, de Souza Luna LK, Eschbach-Bludau M, Lukashev AN, Drosten C: Aichi virus shedding in high concentrations in patients with acute diarrhea. Emerg Infect Dis 2011, 17:1544-1547.

48. Reuter G, Boldizsár A, Papp G, Pankovics P: Detection of Aichi virus shedding in child with enteric and extraintestinal symptoms in Hungary. Arch Virol 2009, 154:1529-1532.

49. Ribes JM, Montava R, Téllez-Castillo CJ, Fernández-Jiménez M, Buesa J: Seroprevalence of Aichi virus in a Spanish population from 2007 to 2008. Clin Vaccine Immunol 2010, 17:545-549.

50. Chen H, Yao Y, Liu X, Xiao N, Xiao Y, Huang Y, Chen Q, Yu S: Molecular detection of human parechovirus in children with acute gastroenteritis in Guangzhou, China. Arch Virol 2013, 159:971-977.

doi:10.1186/1743-422X-11-182

Cite this article as: Yip et al:: Epidemiology of human parechovirus, Aichi virus and salivirus in fecal samples from hospitalized children with gastroenteritis in Hong Kong. Virology Journal 2014 11:182.

\section{Submit your next manuscript to BioMed Central and take full advantage of:}

- Convenient online submission

- Thorough peer review

- No space constraints or color figure charges

- Immediate publication on acceptance

- Inclusion in PubMed, CAS, Scopus and Google Scholar

- Research which is freely available for redistribution 